\title{
The Field Shaping of Aboriginal Cultural Creativities - Taking the Laiji Tribe and the Sandimen Commercial Circle for Example
}

\author{
Meng-Ling Lay, Shu-Hua Gao, and Su-Ping Tan
}

\begin{abstract}
Under the influence caused by the booming mania to the industries of cultural creativity, the aggressive development of culture and economy has become one of the prevailing trends among numerous countries currently. Taiwan is an island nation divergently fused with numerous ethnic groups wherein most researchers and scholars suppose the aboriginal cultures are abundantly featured with domestic indigenous tribes and cultures. The cultures of indigenous tribes are now situated in a setting with particular social changes. The changes make the fields of daily life transformed into the fields of creative cultures with their domains and the concepts of space having gradually been disintegrated, faded away and restructured. In the transforming process, the traditional space and fields of the aboriginals must be further experienced with the dilemma of novel positioning and the reluctance to accept new reforms. This research was conducted by taking the indigenous tribes of cultural creativity, namely the Laiji Tribe and the Sandimen Commercial Circle for example. Also, the analysis was further conducted to find out the types of the fields of cultural creativity and the revolutions of the relevant space and domains.
\end{abstract}

Index Terms-Fields of cultural creativities, impressive commercial circles of indigenous tribes, field shaping.

\section{INTRODUCTION}

Recently, due to the increasing emphasis on cultural creativity industries along with modern people suffering higher stress from daily life, most people are fairly willing to spend most of their leisure time in clean and tranquil mountains, woods and rural areas to immerge themselves deeply in the natural life of agricultural villages, namely the migratory sightseeing activities. To develop cultural tourisms, aboriginal tourisms and the indigenous tribes featured with cultural creativity becomes an upcoming developing trend in the future of the tourism industries.

Taiwan is a typical nation fused with divergent ethnic groups wherein the aboriginal cultures are exactly the very essence with their extreme particularities and cultures. In view of these features, the people of indigenous tribes are now facing an unusual transformation impacting traditional space and domains. Traditional space and domains also vary with the development of touring activities gradually becoming the tourism-oriented cultural creativity industries wherein the so-called traditional space and domains include the domains

Manuscript received May 17, 2013; revised August 17, 2013.

Meng-Ling Lay, Shu-Hua, Gao, and Su-Ping Tan are with the Southern Taiwan University of Science and Technology, Tainan, 710 Taiwan (e-mail molin@mail.stust.edu.tw; vulck189@gmail.com; ma1j4228@stust.edu.tw). and space of for hunting and gathering, old residences and worship centers. In traditional space and domains, these facilities symbolize some meanings looming their social history, spatial layout and power status. Space is exactly the main body formed by environment. Therefore, the migration and transformation of space can be deduced to insight the geographical transformation and background.

In Taiwan, the people of indigenous tribes were Tehran earliest residents in this island. However, due to the intrusion of the Han ethnic groups, the cultures of these indigenous tribes finally gradually changed their staging mainstream to non-mainstream. Actually, these non-mainstream cultures were featured with their uniqueness and particularities extremely. Therefore, nowadays, the Taiwan government starts to protect, conserve and develop tourisms and the activities of ecological trips. As matters stand, these reforms will probably cause the transformation to traditional space and domains wherein these include some substantial contexts like cultures, power, social status and economy. When space was fused into the fields, it is available to construct the value of main bodies. However, under the impact of tourisms, reconstructed or reshaped space, in the process changed into the fields of cultural creativities, it is worthy of our insightful exploration whether these spaces and domains filled with meanings can cater to the market trends through abandoning or accepting the process to shape the fields of cultural creativities.

In this research, the space and domains of cultural creativity made by two different indigenous tribes were taken for example. It aimed to explore the transformation happening to the space and domains of cultural creativity from traditional space and domains among these aboriginal people.

\section{RESEARCH PURPOSES}

This research conducted the case study on the Laiji Tribe of the Alishan Tsou ethnic group and the Sandimen Commercial Circle.

It was meant to study the changes and influence after the traditional space and domains of indigenous people transformed into the fields of cultural creativities. Also, the types of tribes and commercial circles were used to analyze the variation happening to the overall space with the research purposes shown as below:

1) Explore the indigenous tribes of cultural creativity and the space and domains of cultural creativity in Taiwan.

2) Compare the transformation of spatial fields between the Laiji Tribe of the indigenous people and the Sandimen 
Commercial Circle.

3) Propose the suggestions available for the upcoming effort aimed to shape the tribes of cultural creativity and the space of impressive commercial circles.

\section{RESEARCH SUBJECTS}

In this research, the Laiji Tribe of the Tsou indigenous people in Taiwan and the Sandimen Commercial Circle were taken for example.

The Laiji Tribe is located northern to the Alishan Township nearby the upstream of the Alishan Creek and this tribe can be subdivided into two different settlements, namely the Inner Laiji Settlement and External Laiji Settlement. Laiji is also known as "the Eternal Tribe under the Mount Ta" meaning the continuation and legacy. It is a village filled with the atmosphere human cultures and tribal art.

The Sandimen Commercial Circle was promoted by the Local Commercial Circle Revival and Jumping Project proposed by the Ministry of Economy Affairs in 2009. The Sandimen Commercial Circle was guided by the Department of Commercial Affairs at the Ministry of Economy Affairs and it was the first impressive commercial circle aimed at economy development located in aboriginal regions (See Fig. $1)$.

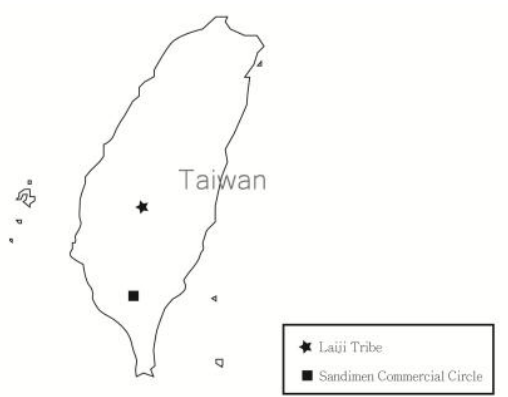

Fig. 1. The Locations of the Laiji Tribe and the Sandimen Commercial Circle

\section{LITERATURE REVIEW}

The particularities and uniqueness of aboriginal cultures had become one of the key items to develop the industries of aboriginal cultural creativities. Through the overall construction and the promotion of regional activities endeavored by domestic communities, under the booming political and economy development, the original life styles had gradually transformed into the fields of cultural creativity filled with tourism efficiency.

This research was focused on the field shaping of the Laiji Tribe and the Sandimen Commercial Circle Tribe mainly discussing the traditional space of the indigenous people and the field shaping as literature analysis.

\section{A. The Tribe and Commercial Circles of Cultural Creativities}

In this research, the Laiji Tribe and the Sandimen Commercial Circle were taken for example to serve as the subjects of literature review.

\section{1) The tribe of cultural creativity-Laiji Tribe}

With the booming fever of the cultural creativity among aboriginal tribes in Taiwan, the traditional foods, living styles and traditional knowledge had become an economy model with experiencing tourism service available.

Due to different circumstances, the tribes of indigenous people naturally developed various living cultures. In 1995, when the first Sanmei Tribe of indigenous people was established in Chiayi County with well-planned management implemented [1]. The cultures of indigenous people were re-created into the industries of cultural creativity founding an important way for the development of modern transformation made by the industries of aboriginal cultures. The definitions of the industries of cultural creativity added the management of creativity marketing into cultural variance. With this, it was available to trigger economy development and cultural transformation.

The cultures of indigenous people were featured with variance and uniqueness. Despite being the original residents in Taiwan, however, the indigenous people were governed by other ethnic groups. For those exotic ethnic groups, the art of indigenous people was held as the non-mainstream cultures. However, the industries of tribal cultural creativity started to make good use of the aboriginal cultures filled with uniqueness to trigger the new development, new management ways, cultural variance, and uniqueness among tribes including the combination of aboriginal people, territories, the plasticity of traditional space, the application and demonstration and production of traditional gears with sufficient features displayed in surrounding fields. The tribal cultural creativity supplied the development opportunities for local talents with further transformation, management and marketing available.

For Laiji Tribe, the landscape was in coordination with domestically traditional industries combined with tribal tales, handicrafts and decorations to serve as the derivatives demonstrating the overall tribal features and developing a tribe with the industries of cultural creativities. Furthermore, tribal tourism economy could be boosted wherein some technological marketing ways were also added to make marketing effect for the tribe reachable.

\section{2) The commercial circles of cultural creativity - the Sandimen commercial circle}

As I-F. Kuei [2] defined, the impressive commercial circles meant the public policies with governmental administration and guidance focusing on some regions aimed to shorten the urban-rural gap and enhance local attraction by integrating the effort from industries, scholars and all aspects of the society. Among them, the environment was themed with domestically particular historical background and traditional cultures to combine the industries of cultural creativity and the products filled with domestic specialties. As such, the overall environment and landscapes were improved, the unique image of a region was created; the community awareness among residents was fused and a commercial environment operated by modern business management was constructed.

As Y. I. Chien [3] contended, the impressive commercial circles could be divided into:

- Urban Impressive Commercial Circle: It was featured with strong purposive and thematic consumption attraction with a wider coverage with the guidance emphasizing the improvement of the commercial service 
environment, full use of public space, shaping and positioning the image of store streets, establishing the common autonomous mechanisms and the planning for upcoming development.

- Regional Impressive Commercial Circle: It was mainly meant to meet the demands of local residents with the coverage of a commercial circle of 3 kilometers roughly. The guidance emphasized the dense commercial activities of retailers with more availability of service items, the improvement of hardware environment, adding other different industries and transaction models to form a self-sufficiency consumption body.

- Featuring Impressive Commercial Circle: It was featured with particular historical background, traditional handicrafts or other tourism resources make the consumption features more purposive and thematic than those of store streets. The guidance emphasized the features of street zones to combine the tourism resources of communities reviving the features of handicrafts or the commercial circle with the effort of overall community construction added.

- Rising Impressive Commercial Circle: It was a base with sparse or even without any commercial gathering activities but the newly established store streets were designed to meet some demands with the guidance emphasis on the analysis of base conditions, planning of traffic flowing lines and public facilities, and the guidance and implementation of business solicitation.

The Sandimen Township was known as "Se-Timor" in Paiwan language and located on the northeastern side by the Ai-Liao Creek. No matter in view of the historical lectures in Qin Dynasty, Dutch Occupation Period or during the period of the during the Nanjing Republic of China, the Paiwan Tribe was never an enclosed group with divergent activities exchanging with other different ethnic groups continuously [4]. The experience of the Sandimen Tribe exchanging with people outside had been lasting for half a century and this history started from the Japanese Occupation Period long before with their own tourism industries well developed. Till now, Sandimen has become the political and cultural center of the Paiwan Tribe in the southern Taiwan. In view of its geographical location, nowadays it is also the central site to the northern Paiwan Tribe, namely a hub of political, economy and social resources [5].

\section{B. Space}

The so-called "space" meant a general term of all locales. Aside from providing the places available to accommodate locales or sites, it could allow people with the accessibility for expansion with their life existing therein [6]. Space was composed of different fields. Non-structure space was added with human behaviors, time and objects to form structured behaviors. Therefore, space could be classified and attributed such as behavioral space, time space and demonstrating, etc.

In view of western philosophy, space was viewed as a receptacle and space meant a kind of involvement to the human world. Leferre divided space into three dimensions, namely space implementation, space symbolization and symbolized space to discuss the genesis of space [7]. In the perception level, it included production, reproduction and social forms. The human behaviors in space included production, use and reconstruction and all belonged to the implementation behaviors in space.

In the perspective of the definitions of space given by different ethnic groups, M. H. Wang [8] contended it could be divided into objectively real space and subjective space. Real space was concretely visible to demonstrate humane art and natural landscapes (such as tribal buildings, dwelling houses, road pavement, handicraft art, fabrics or the colors and patterns of the principal key demonstrated by space).

The space of subjective meanings was given with definitions and titles to form a new title and field endowing the integrity to the groups of space with their own sovereignty of differences arisen. Affected by social norms, the basic demands of space would vary with the changes of time and space [9].

In the traditional space among aboriginal people, most indigenous people resided in natural landscapes and built their houses artificially. Through this situation, it would be available to understand the traditional habits and customs in the traditional space among aboriginal people.

\section{Field}

"Field" could cover numerous kinds of tangible or intangible elements. From the very moment when a concrete spatial filed was created onward, the field started to embrace its social meaning. The mutual relationship network of actors and the social structures caused by the relationship of social groups was exactly the "field" [10]. The formation of any society was always constructed by the fields with a series of class systems such as the political fields created by people and people's power, the economy fields framed by currency and interest and the fields created by cultures.

In field structures, different structures could echo each other. For example, although the economy field and the culture field were two fields sheerly different, yet they could affect mutually in the aspects of economy industries [11]. Therefore, it could be clearly seen the contexts covered fields were complex. From the representation, social classes, systems and social operation could be clearly seen (economy, culture and customs). Through the inner levels, it was available to understand the energy, history and social value of the field. Differently put, the formation of a field meant the both the mental and physical strength arisen from a group of people.

In the perspective of the traditional fields among aboriginal people, it could be roughly classified with culture, economy, power and social status. The culture field meant mother tongues and the influence caused by behavioral patterns. The economy field meant production, hunting and gathering with power-class, identities, genders, ages, social status centered on the tribe, a maternal society. The substantial meanings of these fields all existed in space; therefore, space started to be featured with its subjective value. The China Ethnography Association [12] used to propose that the old commodities of indigenous people were all composed of some common internal contexts like the settlements, the roles of regional development, the history of groups and the types of settlements. Because of the changes happening to settlements, the history of settlements could be revealed accordingly. 


\section{RESEARCH METHOD}

This research was conducted by means of the review of historical literatures, field surveys and interview.

\section{A. The method of the Review of Historical Literatures}

The method of the review of historical literatures means a method purposed to investigate history and its evolution with the technical levels focusing on any facts happened in the past. As S. T. Chen [13] proposed, such a researching method is vested with four different features:

- The feature of time: The origin, rising and disappearance of an event are always traceable. The historical researching method is based on time-axis with the positioning of historical facts.

- The feature of space: The appearance, occurrence inevitability and the sizes of the space and geographical layout of an event are all corrected mutually.

- The feature of interaction: Human beings, time and space are correlated mutually arising complex factors of the event.

- The feature of change: In human history, any event is always affected by different time points and spaces to bring about changes.

The historical method is conducted to track the past historical facades of tribal space and applied domains. From historical information, by using the methods of observation and measurement, the historical material is systematically organized and explained to bring about the correlation to separately independent historical facts as the basis to understand the present and predict the future. Especially, the spatial changes happening to tribal domains is exactly the key interest in event exploration mentioned in this research.

\section{B. The Method of Field Surveys}

With long-term practical experience or the involvement of tribal activities, it is meant to observe and understand the substantially existing phenomenon in tribal life. Meanwhile, by referring to the compiled results from past scientific literatures to fulfill the deficiency in scientific literatures, the in-depth tribal interview for the subjects of the case study is conducted to explore the social relationship happening to the changing records of tribal domains and processes [14]. Field surveys are meant to obtain the in-depth or fact-feed backing information or oral records with the appropriate interview to collect and observe current culture, society and local styles.

\section{The Method of Interviewing}

Interview means the interaction between two different roles. Through the dialogues of asking and answering, the relevant information is obtainable. When the interview is conducted, some nonverbal intentional expression like the facial countenance, tones and postures of the interviewees are also worthy of exploration. Through interviews, some new discussion issues can be found or arisen to serve as the major measuring tool for researches or the supplementary tools during researching processes, or the material applicable to subsequent researching follow-ups. Also, it is easier to enter the core issues deeply. When conversing with interviewees, it is available to evaluate the reliability and authenticity of the answered words from interviewees through interaction [15].
Additionally, it is suitable for special subjects and environment effectively enhancing researching reliability and validity. It can also indirectly improve the response capabilities of the interviewer to train observatory capabilities and the mindsets for problem solving.

\section{RESEARCH ANALYSIS}

Through the analysis of historical literatures, the methods of practical field surveys and interview, this article divides the tribal domains of the indigenous people into the parts of the space and the field. The space means the substantial space like ancient paths, worship centers and the places of old communities. The field can be divided into culture, economy, social status and power with the researching analysis mentioned as follows.

\section{A. The Shaping of the Fields of Cultural Creativity Created by Laiji Tribe}

Laiji is located on the Alishan Township of the Chiayi County, a place mainly composed of Tsou Tribe. Their ancients migrated from a place called Tefuye and named this land as the beautiful tribe under the Mount Ta. This land is densely surrounded by numerous creeks and futile soil wherein most tribal people are conducting agricultural activities now. After the policy of two-day-off-a-week was implemented, such a situation helped the Laiji Tribe to develop their tourism industries. Recently, numerous tourism spots had been established to boost the development of local restaurants, hostels and craft shops.

$70 \%$ of the residents of Laiji Tribe are mainly engaging in agricultural activities now. After the tribe of cultural creativity was founded, they still kept their original lifestyles. However, some changes started happening to the shaping of the fields. In the tribe, there were numerous hostels and craft shops built nearby adjacent landscapes to sustain the development of the principal key of overall tourism business. In view of advantages, the tribe of cultural creativity could keep the tribal features closer to its original facade with the least artificial reconstruction to exert the best tourism value. In view of the mode value of the fields, some facts were described as below:

- Culture - Keep the original cultural features well but just make some changes available;

- Economy - Both original and newly developed economy models are well coexisting;

- Social Status - Due to the administrative divisions made by the government geographically, although the tribe could keep its own original social status. The establishment of the governmental township office also brought some changes;

- Power - The power was changed because of governmental involvement.

In view of the perspective of the space, although the tribe of cultural creativity could keep its original spatial forms, because of tourism-oriented policies, the spatial environment with exclusivity among indigenous people was also changed or even disappeared such as the worship centers, holy lands, ancestral spirits and territories (See Fig. 2). 


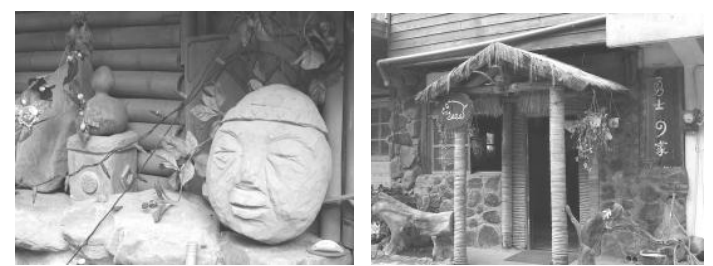

Fig. 2. (a) The building decorations at the Laiji Tribe; (b) the tribal building was changed into a hostel breakfast shop.

\section{B. The Field Shaping of the Cultural Creativity at the Sandimen Commercial Circle}

Based on the information provided by the interviewee, Miss H. C. Shih, the Founder of the Dimor Art Association of Cultural Industries for this research, the concept of the Sandimen Commercial Circle was originated from the proposal of the commercial circle guidance projects created by the Ministry of Economy Affairs in 2005. At that time, all the local residents capable of running stores were convened to participate this project and organize a strategic alliance. In front of every store of the member of the strategic alliance, store signs of strategic alliance were erected (personal communication, May $3^{\text {rd }}, 2013$ ). Also, the government conducted construction and improvement on the commercial circle to substantially create the atmosphere of a commercial circle [16].

Because the Sandimen region was a place mainly composed of the residents of the Paiwan Tribe with glass beads serving as its own local cultural feature. Therefore, when the association started to promote the Sandimen Commercial Circle, the commercial slogan was mainly focused on the Hometown of Glass Beads - Sandimen to act as the local tourism industry openly. As Miss Shi indicated, such an idea was mainly because there had been numerous craftsmen raised from Sandimen and their techniques had been well qualified to meet the demands from customers. Therefore, such a slogan could be promoted to make the tourism atmosphere filled with the totems of glass beads. Tourists could immerge themselves deeply in the atmosphere full of glass beads.

Under such environmental transformation, in view of the advantages, the existing cultures could be well conserved with the valuable tourism worth to promote the development of cultural industries. It could also enhance the economy efficiency of a region. After tourism industries were well established, the influence to cause the value transformation of the field were described as below:

- Culture - The usage of aboriginal mother tongues declined gradually with their behaviors starting to change from sharing or barter into commercial models. Indigenous people started to learn the way how to vend and introduce commodities.

- Economy - Original ways of gathering and hunting started to change into the production and vending of handicrafts with original economy models weakened gradually.

- Social Status - The traditional class status also gradually disappeared. Aside from the traditional models to keep for large occasions, due to governmental policies, the class status among indigenous people gradually became famous without real.
- Power - Due to governmental promotion, power had been gradually shifted to the officials or openly voted or the administrative staffs appointed by the government acting as the communicating role between the government and local residents. The regional development was materialized, but the political power was shifted and transformed.
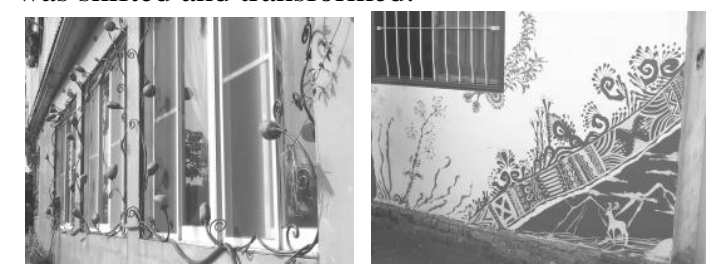

Fig. 3. (a) (b) The creation of the space of the cultural commercial circle.

In space, the Sandimen Commercial Circle is actually located on the Sandimen Township and it is now an important administrative region with the combined image of streets, residences and the administrative center. On Sandimen, most buildings were made by cements wherein numerous natural stuffs were also used for decorations. Such a situation also jumped off the limitation of building layout due to different social classes (See Fig. 3).

\section{Comparison}

In view of the transformation happening to the Laiji Tribe and the Sandimen Commercial Circle, the Laiji Tribe attracted tourists to enter their own territories and when tourists aggressively enter the territories, less destruction was caused by tourists. Because the impressive commercial circles were aggressively promoted by the government, considerable changes were caused. The comparison of the changes happening to the fields in the Laiji Tribe and the Sandimen Commercial Circle was shown as below Table I:

TABLE I: THE TRANSFORMATION OF THE FIELDS OF CULTURAL CREATIVITY

\begin{tabular}{|c|c|c|c|}
\hline Field & Region & Variance & Similarity \\
\hline \multirow[b]{2}{*}{ Culture } & Laiji & $\begin{array}{l}\text { It was available to } \\
\text { keep original } \\
\text { lifestyles because } \\
\text { tourists } \\
\text { aggressively } \\
\text { entered the fields. }\end{array}$ & \multirow{2}{*}{$\begin{array}{l}\text { Traditional } \\
\text { cultures and } \\
\text { tales had been } \\
\text { developed into } \\
\text { commodities. } \\
\text { The Laiji Tribe } \\
\text { mainly viewed } \\
\text { wild boars as the } \\
\text { representative } \\
\text { image of its } \\
\text { development, } \\
\text { but The } \\
\text { impressive } \\
\text { commercial } \\
\text { circle of the } \\
\text { Sandimen } \\
\text { Commercial } \\
\text { Circle was } \\
\text { mainly based on } \\
\text { the industry } \\
\text { manufacturing } \\
\text { glass beads. }\end{array}$} \\
\hline & $\begin{array}{l}\text { Sandimen } \\
\text { Commercial } \\
\text { Circle }\end{array}$ & $\begin{array}{l}\text { Because of } \\
\text { governmental } \\
\text { policies, the } \\
\text { existence of } \\
\text { navigation signs, } \\
\text { installation art and } \\
\text { cultural products } \\
\text { brought more } \\
\text { changes to the } \\
\text { types of tribes. }\end{array}$ & \\
\hline \multirow[t]{2}{*}{ Econoy } & Laiji & $\begin{array}{l}\text { Mainly based on } \\
\text { agriculture and } \\
\text { tourism. }\end{array}$ & \multirow{2}{*}{$\begin{array}{l}\text { Both are now } \\
\text { oriented by } \\
\text { tourism for } \\
\text { economy } \\
\text { development. }\end{array}$} \\
\hline & $\begin{array}{l}\text { Sandimen } \\
\text { Commercial } \\
\text { Circle }\end{array}$ & $\begin{array}{l}\text { Mainly based on } \\
\text { local industries. }\end{array}$ & \\
\hline Society & Laiji & Aside from the & Due to the \\
\hline
\end{tabular}




\begin{tabular}{|c|c|c|c|}
\hline \multirow[t]{2}{*}{ Status } & & $\begin{array}{l}\text { administrative } \\
\text { staffs appointed } \\
\text { by the } \\
\text { government, the } \\
\text { original social } \\
\text { status could be } \\
\text { better kept. }\end{array}$ & \multirow{2}{*}{$\begin{array}{l}\text { arrangement of } \\
\text { administrative } \\
\text { divisions, major } \\
\text { staffs came from } \\
\text { those public } \\
\text { servants openly } \\
\text { voted or the } \\
\text { administrative } \\
\text { staffs appointed } \\
\text { by the } \\
\text { government. }\end{array}$} \\
\hline & $\begin{array}{l}\text { Sandimen } \\
\text { Commercial } \\
\text { Circle }\end{array}$ & $\begin{array}{l}\text { Aside from the } \\
\text { traditional models } \\
\text { better kept for } \\
\text { large occasions, } \\
\text { the original class } \\
\text { status had been } \\
\text { gradually } \\
\text { disappearing } \\
\text { among aboriginal } \\
\text { people. }\end{array}$ & \\
\hline \multirow[b]{2}{*}{ Power } & Laiji & $\begin{array}{l}\text { The government } \\
\text { assigned the } \\
\text { administrative } \\
\text { staffs based on } \\
\text { election results, } \\
\text { but the parts of } \\
\text { traditional power } \\
\text { were still existent. }\end{array}$ & \multirow[b]{2}{*}{$\begin{array}{l}\text { All traditional } \\
\text { classes started to } \\
\text { fade away such } \\
\text { as chiefs and } \\
\text { witches wherein } \\
\text { the situation was } \\
\text { apparent in the } \\
\text { Sandimen } \\
\text { Commercial } \\
\text { Circle. }\end{array}$} \\
\hline & $\begin{array}{l}\text { Sandimen } \\
\text { Commercial } \\
\text { Circle }\end{array}$ & $\begin{array}{l}\text { The government } \\
\text { assigned local } \\
\text { officials and } \\
\text { administrative } \\
\text { staffs to act as the } \\
\text { communicating } \\
\text { roles between the } \\
\text { government and } \\
\text { local residents to } \\
\text { materialize the } \\
\text { development of } \\
\text { every region with } \\
\text { power } \\
\text { transformation } \\
\text { arisen. }\end{array}$ & \\
\hline
\end{tabular}

The transformation after the space was changed into the fields of cultural creativity was shown as Table II:

TABLE II: THE TRANSFORMATION OF SPACE

\begin{tabular}{|c|c|c|}
\hline Region & $\begin{array}{l}\text { Traditional Living } \\
\text { Space }\end{array}$ & $\begin{array}{l}\text { The Space and Fields of Cultural } \\
\text { Creativities }\end{array}$ \\
\hline Laiji & \multirow[b]{2}{*}{$\begin{array}{l}\text { Tribal buildings, } \\
\text { ancient roads, old } \\
\text { community lands, } \\
\text { worship fields, } \\
\text { ancient spirit lands, } \\
\text { hunting lands, } \\
\text { gathering lands and } \\
\text { meeting houses. }\end{array}$} & $\begin{array}{l}\text { Hostels were established. Ancient } \\
\text { roads become touring spots. Craft } \\
\text { shops were established. The tribal } \\
\text { unused space was themed with } \\
\text { the decorations of traditional } \\
\text { tales. Restaurants were themed } \\
\text { with aboriginal dishes. }\end{array}$ \\
\hline $\begin{array}{l}\text { Sandimen } \\
\text { Commercial } \\
\text { Circle }\end{array}$ & & $\begin{array}{l}\text { The illustrative and textual } \\
\text { navigation street signs were } \\
\text { erected. The administrative } \\
\text { buildings of governmental } \\
\text { agencies were founded. Stores, } \\
\text { restaurants and governmental } \\
\text { buildings were established } \\
\text { everywhere. The worship } \\
\text { activities had been held by local } \\
\text { elementary schools. Ancient } \\
\text { roads and houses had been } \\
\text { established and conserved for } \\
\text { demonstration. }\end{array}$ \\
\hline
\end{tabular}

The changes happening to space and fields symbolized the touring tribes were actually featured with exclusivity to their own territories. The exclusivity itself also gradually disappeared. The establishment of governmental policies or administrative regions was also one of the important factors to trigger tribal transformation changed into the development of commodities vended by commercial circles and the establishment of hostels. Such a situation explicated the disappearance or recombination of the cultures, economy and power caused by spatial change after the fields of cultural creativity were changed from touring tribes.

\section{CONCLUSION}

Under the influence caused by touring, aboriginal tribes changed into commercial circles or the tribes of cultural creativity had become the trend of upcoming development. However, in the development process, the influence on the space and fields were concluded as below:

\section{A. The Influence on the Shaping of the Fields of Cultural Creativity}

When the tribal traditional fields were shaped into the fields of cultural creativities, the value of the fields would probably disappear or coexist simultaneously. In view of disappearance, because of tourism-oriented motivations, the cultures or activities inherent to tribes had to be transformed. People had to face the issues that cultures had to become commodities and mother tongues disappeared gradually. In view of recombination, due to the renewal transformation happening to cultures, cultures were re-transformed again. Both could be concluded as below:

\section{1) Laiji tribe}

The influence on Laiji Tribe caused by the shaping of the fields of the cultural creativity showed less external involvement with original fields better kept. The fields of cultural creativity were kept more traditional. Despite the vending activities of craft shops, handicrafts were also well kept with their own cultural traditions inside. The power of the fields was exactly the item affected most.

\section{2) Sandiman commercial circle}

The fields of the Sandimen Commercial Circle inclined to two different levels of recombination and disappearance with original features added with new design concepts to develop novel commodities of cultural creativities. However, it was focused on the subject with the industry of a single feature and it probably causes the disappearance of other industries and cultures. Due to the establishment of the Sandimen Commercial Circle, stores hoped to attract customers' attention. Aside from vending their own commodities, stores also imported clothes and commodities.

\section{B. The Influence on the Shaping of the Space of Cultural Creativities}

In the space shaping process of cultural creativities, the original space norms had been broken. For example, the original buildings were changed into stores, hostels and restaurants. The outdoor artistic decorations originally allowable for tribal chiefs or craftsmen had been experienced with space reproduction or transformation due to the development of the space of cultural creativity by using outdoor decorations and handicraft stuffs. In view of Laiji 
Tribe, hostels, restaurants and craftsmen's shops were established in the tribe. The impressive commercial circle was designed with roads, stores and DIY studios accordingly.

The shaping of the fields of cultural creativities, the maintenance of original value and the generation of new value, the way how to make balance reachable after the space was recombined were exactly the critical issues for the planners considering cultural preservation or reconstruction. Aside from affecting cultural economy, social power and spatial environment, the transformation of field space mainly affected the existing living model of aboriginal people.

I.-F. Chen \& W. C. Chang [17] also mentioned the self-identity consciousness of the indigenous people. Numerous tribes started to aggressively meditate and try to solve some issues arisen from cultural legacy, the destruction of the Mother Nature and domestic economy. However, under the influence caused by economic pressure, the indigenous people are forced to abandon their original social value catering to the superficial demands from tourists. They adopt unauthentically sumptuous ways to demonstrate their own culture and customs and this situation also changes to the overall fields. Such factors to change traditional culture are exactly the issues that we are thinking about in the future.

\section{REFERENCES}

[1] Y. L. Chen, The Taiwanese Indigenous Peoples, Taipei: The Bookrep Publisher, 2004, pp. 207.

[2] I.-F. Kuei, "The marketing strategies of the Image Business District for aboriginals The case study on Sandimen Township in Taiwan," the Dissertation for the Master's Degree of the Graduate Institute of High-Level Pubic Policies, National Sun Yat-Sen University, 2010.

[3] Y.-I. Chien, "A study of Store Street organization operation," the Dissertation for the Master's Degree of the Graduate Institute of Leisure Services Management, Chaoyang University of Technology, 2000.

[4] Y. M. Kuo, "The Commercialization of Sandimen Clothes and Accessories Along with its Contextual Change," the Dissertation of the Master's Degree of the Graduate Institute of Anthropology, National Tsing Hua University, 2006.

[5] K. M. Chiang, "The modern identity and transformation of the innovative identity arisen from the cultural industries of Sandimen," the Dissertation for the Master's Degree of the Graduate Institute of Ethnic Relations and Culture, National Donghua University, 2003.

[6] J. L. Tsai, "The Study of the installation art of space, locale and location and spatial phenomenology," Taipei: The Memoirs of the Academic Symposium of Traditional Art: The Theories and Materialization of the Preservation of Folk Art, 2006, pp. 129.

[7] C. H. Wang, Fluidity, space and society: 1991-1997 Selected Dissertations, Taipei: The Garden City Publisher, 1998, pp. 72-73.
[8] M. H. Wang, S. S. Wang, and C. C. Pu, The History of Taiwanese Indigenous Peoples-Tsou History, Taipei: The National Taiwan Historica, 2001.

[9] H. Hanan, "Modernization and cultural transformation: The Expansion of traditional Batak Toba House in Huta Siallagan," Procedia-Social and Behavioral Sciences, vol. 50, pp. 800-811, Bangkok, Thailand, July 16-18, 2012.

[10] M. F. Wu, "The field energy-the correspondence between limb performance art and representation fields," The FGU Graduate Institute of Human Culture, 2004.

[11] S. H. Tsou and C. C. She, "The art competition of social fields: The correlation between the Taiwanese artists of the new generation and display space," The Graduate Institute of Art Management, Yuan Ze University, The Dissertation for Master's Degree, 2009.

[12] I.-C. Liu, P. L. Wu, A. H. Cheng, C. H. Chen, and I.-H. Hu, "The Study on the ruins of Taiwanese Indigenous peoples," The Council of Indigenous Peoples, Executive Yuan: The China Ethnography Association, 2000, pp. 34-41.

[13] S.-C. Chen, "The Method of Historical Literatures", in The Design of Researching Methods, Taipei: The Chuanhua Publisher, 2010, ch. 3, pp. 39.

[14] H.-Y. Qu, The Methods of Investigation and Research, Taipei: The Sanmin Publisher, 2007.

[15] L.-Y. Ruan, "The Method of Interviewing," in The Design of Researching Methods, Taipei: The Chuanhua Publisher’ 2010, ch. 8, pp. 125-147.

[16] Ministry of Economy Affairs (January 2013). Enhance the competitiveness of district, counseling to strengthen soft power Electronic Publication of Creative Broadwood. [Online]. vol. 13, pp. 1. Available: http://gcis.nat.gov.tw/ebook/book-cont-201302.html\#/2

[17] I.-F. Chen and W. C. Chang, "The strategies from the extension of colonization to development: The historical analysis of the tourism of the indigenous people," presented at the Graduate Institute of Development Studies of the National Chengchi University, the 1st Annual Meeting of Development Studies, November 28-29, 2009.

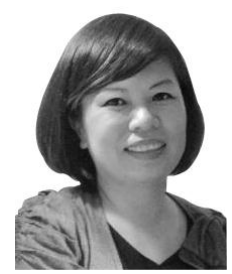

Meng-Ling Lay is a PhD of the Graduate School of Design at the National Yunlin University of Science and Technology in Taiwan.

In August, 2011, she instructed as an assistant professor at the department of Visual Communication Design, the Southern Taiwan University of Science and Technology.

Before holding her instruction at the Southern Taiwan University of Science and Technology, she used to instruct at the Asia-Pacific Institute of Creative Technology and the Tran world Institute of Technology. She has spent a long time endeavoring the development of regional culture industries on the Nantou County and Yunlin County. She also enthusiastically involves in the promotion for the revival of indigenous culture and industries.

Shu-Hua Gao and Su-Ping Tan are graduate students at the Southern Taiwan University of Science and Technology, Tainan, 710 Taiwan. 